\title{
EVALUASI MESIN FILLING PADA BAGIAN PRODUKSI PT. DHARANA INTI BOGA (SUNTORY GARUDA)
}

\author{
${ }^{1)}$ Suradi, ${ }^{2)}$ Ahmad Hanafie, ${ }^{3)}$ Muhammad Rusdi, ${ }^{4)}$ Muzdalifah \\ ${ }^{1,2)}$ Dosen Program Studi Teknik Industri Fakultas Teknik Universitas Islam Makassar \\ ${ }^{3,4)}$ Mahasiswa Program Studi Teknik Industri Universitas Islam Makassar \\ Jl. PerintisKemerdekaan KM 9 No 29 Kampus UIM, Telp 0411-588-167 \\ Email:. ${ }^{1)}$ suradi.dpk@uim-makassar.ac.id, ${ }^{2)}$ ahmadhanafie.dty.@uim-makassar.ac.id \\ ${ }^{3)}$ muhrusli45@ gmail.com, ${ }^{4)}$ ifhamuzdalifah08@ yahoo.co.id
}

\begin{abstract}
ABSTRAK
PT. Dharana Inti Boga (Suntory Garuda) merupakan perusahaan yang memproduksi minuman ready to drink yang beroperasi sejak tahun 2009. Yang harus diperhatikan dalam perusahaan minuman adalah efektifitas kerja mesin filling yang menjadi proses inti terbentuknya sebuah produk. Apabila terjadi kerusakan mesin filling maka akan menyebabkan terganggunya sistem produksi dan efeknya adalah menurunnya efektifitas produksi karena target produksi tidak tercapai dan mesin dapat menghasilkan waste yang dapat mengakibatkan kerugian besar. Metode penelitian yang digunakan adalah Define, Measure, Analyze, Improve dan Control (DMAIC). DMAIC adalah sebuah siklus improvement yang berbasis kepada data (performance data), yang digunakan untuk meningkatkan, mengoptimasi dan menstabilkan desain dan proses bisnis pada suatu perusahaan. Tahapan pertama yang dilakukan yaitu melakukan pendefinisian bagian-bagian mesin filling yang dapat menghasilkan waste kemudian dilanjutkan dengan pengukuran jumlah waste agar diketahui waste yang paling memberikan kontribusi terhadap menurunnya efektifitas mesin filling. Adapun waste yang paling banyak dihasilkan adalah waste cair yang diakibatkan oleh overflow filler yang tinggi dan pengisian aktuator yang tidak stabil. Untuk itu maka harus dilakukan perbaikan untuk melaksanakan tindakan peningkatan dan pengendalian kualitas. Dengan adanya pengendalian kualitas diharapkan masalah waste dapat segera diatasi, dan tidak terulang kembali.
\end{abstract}

Keyword : DMAIC, Waste, Mesin Filling.

\section{PENDAHULUAN}

Perkembangan industri makanan dan minuman kemasan semakin meningkat. Hal ini mendorong bertambahnya pelaku-pelaku usaha, baik yang berskala kecil maupun berskala besar. Euromonitor yang merupakan lembaga survey riset pasar internasional memperkirakan pertumbuhan rata-rata per tahun pasar makanan dan minuman dalam kemasan dan minuman ringan selama 20132017 akan berada di atas angka 10\%, termasuk diantaranya minuman Ready To Drink (RTD) tea yang pertumbuhan pasarnya dapat mencapai 13, 7\% (Mandiri, 2015).

Pertumbuhan pasar yang cepat dan besar ini membuat persaingan industri semakin ketat. Para produsen berlomba untuk dapat menghasilkan produk yang bermutu sesuai dengan keinginan konsumen. Dalam upaya memenuhi keinginan konsumen, produsen harus mampu mengendalikan mutu produk yang dihasilkan.

Kualitas dari produk yang dihasilkan oleh suatu perusahan ditentukan berdasarkan ukuran-ukuran dan karakteristik tertentu. Walaupun proses-proses produksi telah dilaksanakan dengan baik, namun pada kenyataanya masih banyak ditemukan terjadinya kesalahan dimana kualitas produk yang dihasilkan tidak sesuai dengan standar yang telah ditentukan oleh perusahaan atau dengan kata lain produk yang dihasilkan mengalami kerusakan atau cacat produk. 
Upaya suatu perusahaan dalam mengendalikan mutu produk merupakan bagian dari proses produksi. Pada proses produksi, produk yang dihasilkan harus terkontrol, mulai dari tahap awal proses hingga ke tangan konsumen, sesuai dengan spesifikasi atau persyaratan, selalu melakukan perbaikan saat terjadi penyimpangan atau ketidaksesuaian antara produk yang dihasilkan dengan standar yang telah ditetapkan.

Proses produksi yang tidak terkontrol berpotensi menghasilkan produk cacat yang tinggi. Bagi perusahaan, cacat produksi adalah hal yang sangat dihindari. Produk yang cacat tidak dapat dijual, atau dijual dengan harga rendah. Kelancaran dan keberhasilan proses produksi sangat ditentukan oleh kondisi mesin-mesin produksi, peralatan pendukung dan ketersediaan bahan baku nya. Berdasarkan permasalahan diatas, maka perlu untuk mengambil langkah-langkah penyempurnaaan untuk mengurangi kecacatan dari produk yang dihasilkan utamanya pada kinerja mesin filling yang digunakan.

\section{METODOLOGI PENELITIAN}

Penelitian ini akan dilaksanakan di bagian produksi PT. Dharana Inti Boga yang terletak di JL Poros Malino Km.21 Kecamatan Bontomarannu Kabupaten Gowa pada bulan Juni 2017.

Alat dan bahan yang digunakan dalam proses penelitian yaitu :

1. Unit Mesin Filling

2. Kamera

3. Cup

4. Seal

5. Produk semi finish goods

Adapun prosedur penelitian yang digunakan antara lain sebagai berikut :

1. Survei Pendahuluan

2. Studi Literatur

3. Identifikasi Masalah

4. Pengumpulan Data

Adapun data yang diperoleh pada dari penelitian ini adalah:

1. Data primer

2. Data sekunder
Dalam menganalisa masalah maka penulis menggunakan analisis sebagai berikut:

1. Data kuantitatif, yaitu analisis yang dilakukan terhadap data yang diperoleh dari perusahaan tentang data-data hasil pengamatan dan observasi.

2. Data kualitatif, yaitu penulis mengemukkan teori atau konsep tentang hal yang menyangkut dengan masalahmasalah yang dibahas dalam penelitian ini dengan melihat literatur-literatur yang ada baik dari buku, jurnal, skripsi maupun dari internet.

Data yang telah terkumpul kemudian diolah dengan menggunakan prosedur Six Sigma yaitu Define, Measure, Analyze, Improve dan Control (DMAIC).

\section{ANALISA DAN PEMBAHASAN}

Berdasarkan hasil pengumpulan data yang didapatkan pada penelitian di PT Dharana Inti Boga (Suntory Garuda) melalui i dengan tim operasional produksi, pengamatan langsung pada saat proses produksi, dan mempelajari laporan kegiatan produksi maka didapatkan data sebagai berikut :

\subsection{Define}

Define merupakan tahap pendefinisian bagian-bagian dari mesin filling, sehingga dapat diketahui bagian-bagian mesin filling yang dapat menyebabkan waste selama proses produksi dan jenis-jenis waste yang terjadi.

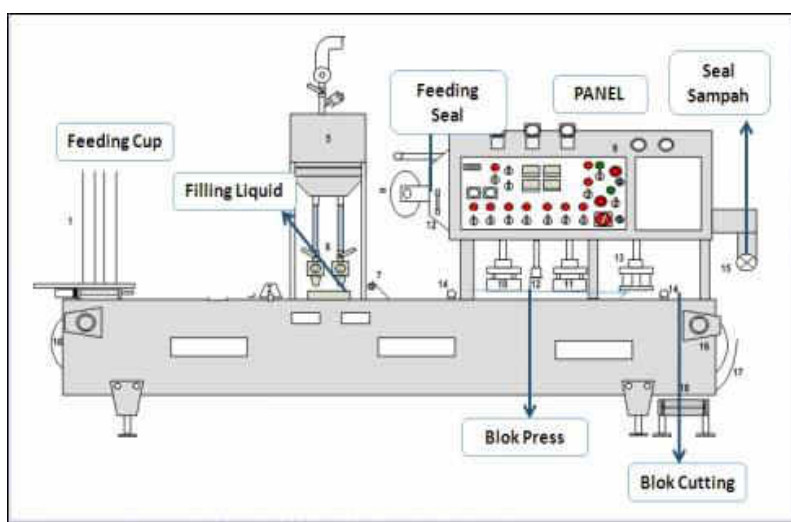

Gambar 1. Komponen Mesin filling (Sumber : GarudaFood)

Masalah yang diakibatkan oleh masalah mesin filling dapat dirincikan sebagai berikut: 

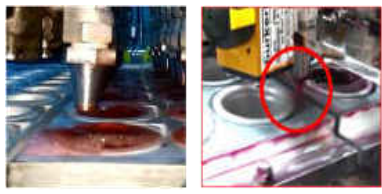

Overtlow Filler

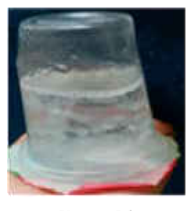

Kurang Isi

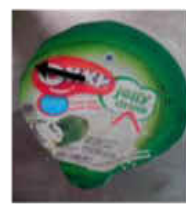

Seal Miring

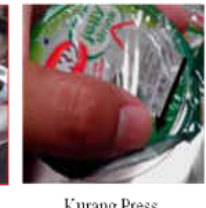

Kurang Press

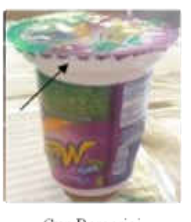

Cup Bergerigi

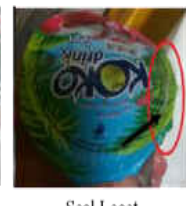

Seal Lece

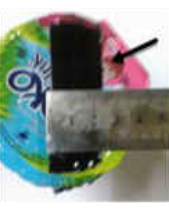

Sambungan Seal
Gambar 2. Jenis Waste (Sumber : GarudaFood)

\subsection{Measure}

Pada tahap pengukuran (measure) berguna untuk menvalidasi permasalahan, mengukur atau menganalisis permasalahan dari data yang ada. Measure adalah suatu tindakan yang bertujuan untuk mengukur dimensi kinerja produk, proses dan aktivitas lainnya. Dalam tahap ini akan ditetapkan Critical To Quality (CTQ) prioritas.

Tabel 1. Jumlah Waste Terhadap Input Produksi

\begin{tabular}{|c|c|c|c|c|}
\hline No. & Waktu & $\begin{array}{c}\text { Jumlah } \\
\text { Input } \\
\text { Produksi } \\
\text { (psc) } \\
\end{array}$ & $\begin{array}{c}\text { Jumlah } \\
\text { Waste } \\
\text { (psc) }\end{array}$ & $\%$ \\
\hline 1 & Jan-16 & $10,821,017$ & 125,910 & $1.16 \%$ \\
\hline 2 & Feb-16 & 9,890826 & 119,642 & $1.21 \%$ \\
\hline 3 & Mar-16 & $8,381,799$ & 87,217 & $1.04 \%$ \\
\hline 4 & Apr-16 & $8,554,966$ & 90,886 & $1.06 \%$ \\
\hline 5 & May-16 & $10,154,248$ & 114,445 & $1.13 \%$ \\
\hline 6 & Jun-16 & $5,649,673$ & 63,786 & $1.13 \%$ \\
\hline 7 & Jul-16 & $9,938,590$ & 47,215 & $0.68 \%$ \\
\hline 8 & Agu-16 & $10,449,903$ & 92,565 & $0,89 \%$ \\
\hline 9 & Sep-16 & $13,073,568$ & 154,020 & $1.18 \%$ \\
\hline 10 & Okt-16 & $12,782,980$ & 173,628 & $1.36 \%$ \\
\hline 11 & Nov.-16 & $10,246,931$ & 116,758 & $1.14 \%$ \\
\hline 12 & Des-16 & $10,142,763$ & 74,177 & $0.73 \%$ \\
\hline 13 & Jan-17 & $11,363,388$ & 57,095 & $0,50 \%$ \\
\hline 14 & Peb-17 & $12,165,533$ & 42,729 & $0.35 \%$ \\
\hline 15 & Mar-17 & $10,155,214$ & 43,773 & $0.50 \%$ \\
\hline 16 & April-17 & $13,366,769$ & 66,268 & 0,50 \\
\hline Total & & $164,140,170$ & $1,470,115$ & $0,90 \%$ \\
\hline \multicolumn{2}{|c|}{ Rata-rata } & $10,258,761$ & 91,882 & $0,90 \%$ \\
\hline
\end{tabular}

Tabel 2. Penetapan Urutan Critical To Quality (CTQ)

\begin{tabular}{lrrr}
\hline \multicolumn{1}{c}{ Jenis Waste } & \multicolumn{1}{c}{ Jumlah } & Percent & Kumulatif \\
\hline Waste Cair & 582,233 & $39.60 \%$ & $39.60 \%$ \\
Kurang Press & 495,887 & $33.73 \%$ & $73.34 \%$ \\
Kurang isi & 158,178 & $10.76 \%$ & $84.10 \%$ \\
Seal miring & 59,096 & $4.02 \%$ & $88.12 \%$ \\
Sambungan Seal & 58,826 & $4.00 \%$ & $92.12 \%$ \\
Seal lecet & 38,333 & $2.61 \%$ & $94.72 \%$ \\
Bocor Seal & 31,584 & $2.15 \%$ & $96.87 \%$ \\
Bocor terjepit & 12,488 & $0.85 \%$ & $97.72 \%$ \\
Seal Pecah & 8,003 & $0.54 \%$ & $98.27 \%$ \\
Cup Pecah & 6,980 & $0.47 \%$ & $98.74 \%$ \\
Bergerigi & 6,939 & $0.47 \%$ & $99.21 \%$ \\
Penyok & 6,276 & $0.43 \%$ & $99.64 \%$ \\
Others & 5,292 & $0.36 \%$ & $100.00 \%$ \\
\hline \multicolumn{1}{c}{ Total } & $\mathbf{1 , 4 7 0 , 1 1 5}$ & - & - \\
\hline
\end{tabular}

\subsection{Analyse}

Tahap ketiga adalah proses Analysis. Dimana dalam tahap ini akan diuraikan variasi penyebab khusus (Special Causes Variation) dalam proses Produksi. Dalam penelitian ini digunakan Fishbone Diagram untuk mengetahui penyebab waste tersebut.

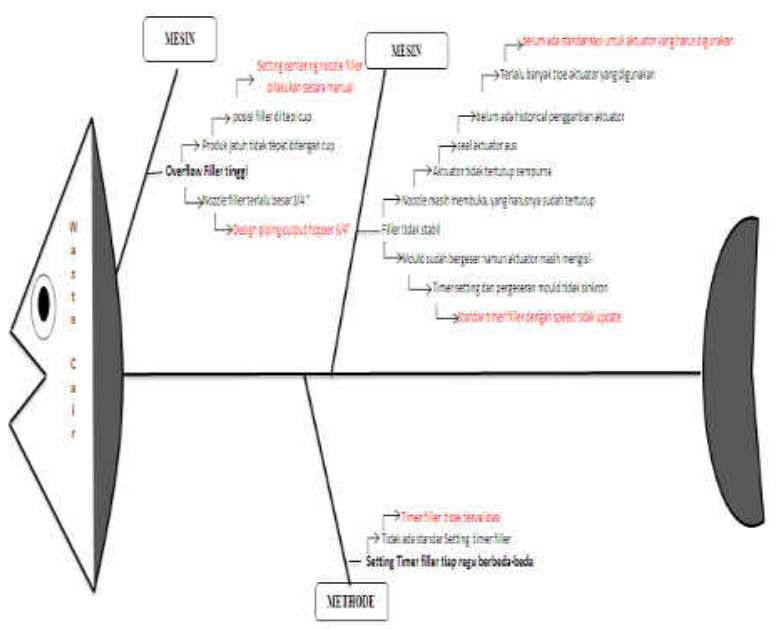

Gambar 3. Fishbone Diagram Untuk Waste Cair

\subsection{Improve}

Improve merupakan rencana tindakan untuk melaksanakan tindakan peningkatan kualitas. Setelah mengetahui penyebab waste cair maka disusun suatu rekomendasi atau usulan tindakan perbaikan secara umum dalam upaya menurunkan waste cair produk sebagai berikut 
Tabel 3. Usulan Perbaikan

\begin{tabular}{|c|c|c|}
\hline Unsur & $\begin{array}{c}\text { Faktor } \\
\text { Penyebab }\end{array}$ & Rekomendasi \\
\hline \multirow[t]{4}{*}{ Mesin } & $\begin{array}{l}\text { 1. Design } \\
\text { piping output } \\
\text { hopper } 3 / 4 \text { ", }\end{array}$ & $\begin{array}{l}\text { 1. Modifikasi nozzle filler dari } \\
3 / 4 \text { "menjadi } 1 / 2 \text { ". Dengan diameter } \\
\text { valve yang besar maka jumlah } \\
\text { overflow yang terjadi saat akhir } \\
\text { filler akan lebih banyak }\end{array}$ \\
\hline & $\begin{array}{l}2 . \quad \text { Setting } \\
\text { centering } \\
\text { noozle filler } \\
\text { dilakukan } \\
\text { secara manual }\end{array}$ & $\begin{array}{l}\text { 2. Membuat plat centering nozzle } \\
\text { filler. Dengan plat centering } \\
\text { nozzle filler maka produk jatuh } \\
\text { pas di tengah cup sehingga tidak } \\
\text { ada produk yang terbuang }\end{array}$ \\
\hline & $\begin{array}{l}\text { 3. Belum ada } \\
\text { standarisasi } \\
\text { untuk aktuator } \\
\text { yang harus } \\
\text { digunakan }\end{array}$ & $\begin{array}{l}\text { 3. Pembuatan standar aktuator } \\
\text { yang digunakan. Life time seal } \\
\text { actuator yang tidak teridentifikasi } \\
\text { mengakibatkan tidak } \\
\text { terlaksananya mantenance yang } \\
\text { tepat waktu }\end{array}$ \\
\hline & $\begin{array}{l}\text { 4. Standar timer } \\
\text { filler dengan } \\
\text { speed } \\
\text { update }\end{array}$ & $\begin{array}{l}\text { 4. Pembuatan standar timer filler } \\
\text { untuk tiap kategori produk } \\
\text { Setting timer filler yang tanpa } \\
\text { adanya standarisasi yang valid } \\
\text { mengakibatkan operator mencari } \\
\text { settingan berdasarkan persepsi } \\
\text { masing masing yang terbaik } \\
\text { secara subjektif }\end{array}$ \\
\hline Metode & $\begin{array}{l}\text { Setting } \\
\text { tiap } \\
\text { berbeda }\end{array}$ & $\begin{array}{l}\text { Pembuatan standar timer filler } \\
\text { kategori produk. Setting timer } \\
\text { filler yang tanpa adanya } \\
\text { standarisasi yang valid } \\
\text { mengakibatkan operator mencari } \\
\text { settingan berdasarkan persepsi } \\
\text { masing masing yang terbaik } \\
\text { secara subjektif }\end{array}$ \\
\hline
\end{tabular}

Berikut data setelah perbaikan yang dilakukan pada bulan Mei 2017 sampai dengan Juli 2017.

Tabel 4. Data Setelah Perbaikan

\begin{tabular}{llrrr}
\hline No. & Waktu & $\begin{array}{c}\text { Jumlah Input } \\
\text { Produksi } \\
(\mathrm{psc})\end{array}$ & $\begin{array}{l}\text { Waste } \\
\text { Cair }\end{array}$ & $\%$ \\
\hline 1 & May-17 & $16.811,461$ & 5,043 & $0,03 \%$ \\
2 & Jun-17 & $8.974,363$ & 3,850 & $0.04 \%$ \\
3 & Juli-17 & $8.800,960$ & 3,520 & $0,04 \%$ \\
\hline \multicolumn{2}{l}{ Total } & $34.386,783$ & 12.414 & $0,04 \%$ \\
\hline \multicolumn{2}{l}{ Rata-rata } & $11.528,928$ & 4,138 & $0,04 \%$ \\
\hline
\end{tabular}

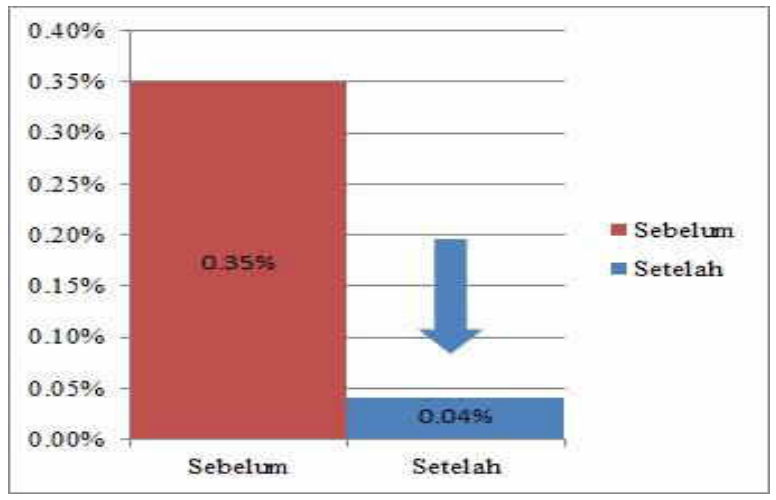

Gambar 4. Grafik sebelum vs sesudah Perbaikan

\subsection{Control}

1. Melakukan perawatan dan perbaikan mesin secara berkala.

2. Melakukan pengawasan terhadap kinerja proses produksi agar mutu barang yang dihasilkan lebih baik.

3. Melakukan pencacatan waste cair setiap hari dari masing- masing jenis produk, yang dilakukan oleh operator filling.

4. Melaporkan hasil pencatatan waste cair kepada supervisor.

5. Total waste cair dalam periode satu bulan dicantumkan dalam montly report.

\section{PENUTUP}

\subsection{Kesimpulan}

1. Jenis-jenis waste yang disebabkan oleh mesin filling pada proses produksi PT. Dharana Inti Boga (Suntory Garuda) Periode 2016 - 2017 yaitu waste cair sebanyak 582.233 pcs, kurang press sebanyak 495.887, kurang isi sebanyak 158.178 pcs, seal miring 59.096 pcs, sambungan seal sebanyak 58.826 pcs, seal lecet sebanyak 38.333 pcs, bocor seal sebanyak 31.584 pcs, bocor terjepit sebanyak 12.488 pcs, seal pecah 8.003 pcs, cup pecah sebanyak 6.980 pcs, bergerigi sebanyak 6.939 pcs, penyok sebanyak 6.276 pcs. Berdasarkan hasil pengolahan data dengan menggunakan metode six sigma diketahui bahwa penyebab waste tertinggi dikualifikasikan sebagai Critical To Quality adalah waste cair sebanyak $39.60 \%$. 
2. Bagian-bagian mesin filling yang menjadi penyebab waste cair yang paling dominan adalah bagian nozzle filler yang ukurannya terlalu besar, posisi yang tidak pas, timer yang tidak sinkron dengan perpindahan mould dan actuator yang aus karena belum adanya standarisasi actuator yang harus digunakan.

3. Dalam tahapan Improve dapat diketahui terdapat beberapa usulan perbaikan untuk mengurangi jumlah waste cair, usulan tersebut yaitu:

a. Memodifikasi ukuran noozle filler dari 3/4" menjadi 1/2". Dengan diameter valve yang besar maka jumlah overflow yang terjadi saat akhir filler akan lebih banyak beberapa unsur yaitu manusia, mesin(peralatn) dan bahan baku.

b. Membuat plat centering nozzle filler. Dengan plat centering nozzle filler maka produk jatuh pas di tengah cup sehingga tidak ada produk yang terbuang

c. Pembuatan standar aktuator yang digunakan. Life time seal actuator yang tidak teridentifikasi mengakibatkan tidak terlaksananya mantenance yang tepat waktu

d. Pembuatan standar timer filler untuk tiap kategori produk Setting timer filler yang tanpa adanya standarisasi yang valid mengakibatkan operator mencari settingan berdasarkan persepsi masingmasing yang terbaik secara subjektif

\section{DAFTAR PUSTAKA}

Ahyari, Agus. 1980. Management Produksi II (pengendalian Produksi). BPFE UGM.Yogyakarta.

D. Manggala, 2005. Mengenal Six Sigma Secara Sederhana. Email d_manggala@yahoo.com.

Evans dan Lindsay. 2007. Pengantar Six Sigma: An Introduction to Six Sigma and Process Improvement. Penerbit Salemba Empat. Jakarta.

Fardiaz, S. 1992. Mikrobiologi Pangan Lanjut. PAU Pangan dan Gizi IPB. Bogor.

Gazpers, Vincent. 2011. Sistem Manajemen Kinerja Terintegrasi Balanced Scorecard dengan Six Sigma untuk Organisasi Bisnis dan Pemerintah. PT Gramedia Pustaka Utama. Jakarta

Holpp, Larry dan Pande, Peter S. 2002. What Is Six Sigma, Berpikir Cepat Six Sigma. Penerbit Andi. Yogyakarta.

Honig, P. 1963. Princples of sugar Technology Vols 1-3. Elsevier. New York.

Koswara, S. 2009. Minuman Isotonik. Ebookpangan.com.

Mandiri, PT Bank. 2015. Update Industry: Makanan dan Minuman (online). (http://mandiri-institute.id/industry-

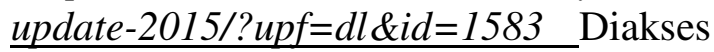
4 Mei 2017).

Mulyadi, 2007. Sistem Perencanaan dan Pengendalian Manajemen. Salemba Empat. Jakarta.

Winarno, F.G. 1973. Air untuk Industri Pangan. Departemen Teknologi Hasil Pertanian, FATEMETA, IPB. Bogor.

Manual HACCP Line HTST. MM-1. Gowa. PT. Dharana Inti Boga (GARUDA FOOD). 2013

Ahyari. (1990). Manajemen Produksi. Edisi keempat. Jilid kedua. Yogjakarta: BPFE.

Assauri, S. (1998). Manajemen Operasi dan Produksi. Jakarta: LP FE UI.

Dorothea, W. A. (2004). Pengendalian Kualitas Statistik (Pendekatan Kuantitatif dalam Manajemen Kualitas). Yogyakarta: ANDI.

E.Wood, B. (1989). Managemen Produksi dan Operasi. Edisi keenam Jilid kedua. Jakarta: Erlangga.

Gasperz, V. (2005). Total Quality Management. Jakarta: PT. Gramedia Pustaka Utama. 